\title{
Comparison of EEG Changes Induced by Action Execution and Action Observation
}

\author{
Ji Young Kim', Yu-Min Ko², Ji Won Park' \\ 'Department of Physical Therapy, College of Medical Science, Catholic University of Daegu, Gyeongsan; ${ }^{2}$ Department of Physical Therapy, \\ Gangneung Yeongdong College, Gangneung, Korea
}

Purpose: Recent electrophysiological studies have shown that the sensorymotor cortex is activated during both actual action excuted by themselves and observation of action performed by other persons. Observation of action based on mirror neuron system can be used as a cognitive intervention to promote motor learning. The purpose of this study was to investigate the brain activity changes during action observation and action execution using EEG.

Methods: Thirty healthy volunteers participated and were requested to perform hand action and to observe the video of hand action performed by another person. The EEG activity was evaluated by a method which segregated the time-locked for each condition. To compare the differences between action observation and execution, the Mu suppression and the relative band power were analysed.

Results: The results showed significant mu suppression during the action observation and execution, but the differences between the two conditions were not observed. The relative band power showed a significant difference during the action observation and execution, but there were no differences between the two conditions.

Conclusion: These results indicate that action execution and observation involve overlapping neural networks in the sensorymotor cortical areas, proposing positive changes on neurophysiology. We are expected to provide information related to the intervention of cognitive rehabilitation.

Keywords: Electroencephalography, Mu rhythm, Relative band power, Action observation

\section{서 론}

뇌공학의 발전을 바탕으로 인간의 중추신경계는 제한적이지만 손상 된 구조와 기능을 일부 회복시킬 수 있는 능력을 가지고 있고, 또한 병변으로 유발된 환경의 변화에 적응할 수 있는 능력을 가지고 있음 이 밝혀지고 있다. 이를 신경가소성(neural plasticity)에 의한 운동기 능회복이라 하고, ${ }^{2}$ 다양한 신체적 움직임을 통해 신경가소성을 증진 시키기 위한 치료적 중재가 지속적으로 제공되고 있다. 그러나 신체 를 움직일 수 없는 대상자에게는 실시할 수가 없으므로 인지적 측면 을 고려한 신체를 사용하지 않는 대안적 훈련방법이 고려돼야 한다. 최근에 활발히 연구되고 있는 동작관찰(action observation) 훈련은 동 작과 관련된 영상관찰을 통해 실제적 움직임 없이 해당 동작을 반복 적으로 훈련하는 방법으로, ${ }^{4}$ 거울신경시스템의 활성에 기반하고 있 다. ${ }^{5}$ 거울신경시스템은 우리가 실제로 동작을 수행하거나, 유사한 동
작을 관찰할 때 활성화되는 감각운동신경으로, ${ }^{6}$ 실제적 움직임 시와 동일한 운동사슬의 신경회로 흥분을 통해 관련된 뇌 영역의 잠재적 활성을 만들어내게 된다.,7

뇌전도(electroencephalogram, $\mathrm{EEG)}$ 를 통해 측정되는 뇌 진동(brain oscillations)은 뇌신경의 흥분성에 대해 협응된 형태로 율동적 변화 를 나타내고, 이러한 진동 변화는 연결된 신경조직 간의 효율적인 상 호작용을 반영한다고 가정되고 있다. 동작관찰과 관련된 뇌진동의 변화를 분석하기 위한 대표적인 방법으로는 뮤리듬(mu rhythm) 분 석과 상대파워분석이 있다. 뮤리듬은 내부적 사건이나, 외부적 자극 에 의해 자발적으로 생성되는 전기생리학적인 신호로 1950 '에 처음 발견되어 central, rolandic, sensorimotor, wicket, 혹은 arceau rhythm으 로 알려져 있다.9-11 8-13 Hz대역에서 감각정보 혹은 운동정보 입력이 없을 때 감각운동피질(sensory-motor cortex)에서 기록되므로 피질의 휴식상태를 반영한다 할 수 있다. ${ }^{2}$ 최고치는 개인의 휴식상태에서 
나타나고, ${ }^{13,14}$ 운동 실행(execution) 및 관찰에 의해 비동기화(desynchronization) 혹은 약화된다. ${ }^{15,16} \mathrm{EEG}$ 를 통해 기록되는 뇌파의 변동 은 약 1-60 Hz의 주파수대역에서 전위변동을 나타내게 되는데, ${ }^{17}$ 측정 되는 주파수 영역에 따라서 델타파(delta: 1-4 Hz), 세타파(theta: 4-8 Hz), 알파파(alpha: 8-13 Hz), 베타파(beta: 13-30 Hz), 감마파(gamma: 30-60 $\mathrm{Hz}$ )로 분류하게 된다. 상대파워(relative band power)는 전체 주파수 영 역의 절대파워에 대한 특정 주파수 영역의 절대파워 비율을 뜻하는 것으로, 주파수 대역별로 나누어 분석하면 우세한 주파수 영역을 파 악할 수 있고, 활성화된 뇌 기능 활성을 확인할수 있는장점이 있다.

지금까지 운동기능의 학습촉진을 위한 인지적 중재의 일환으로 동작관찰을 근골격계 재활, 신경계 재활 등 다양한 분야에 적용하려 는 연구가 많이 시도되어오고 있으나, ${ }^{6,18,19}$ 대부분 동작관찰훈련과 신 체훈련을 병행하여 나타난 기능적 변화에만 관심을 기울여왔고 뇌 파진동 변화를 통해 신경생리적학인 변화를 분석한 연구는 미흡한 실정이다. 또한 뮤리듬 혹은 상대파워만을 이용한 단일 분석을 실시 하였고 두 방법 모두를 적용하여 변화를 비교분석한 연구는 거의 발 표되지 않고 있다

본 연구에서는 휴식 시, 동작관찰 시, 동작실행 시의 뇌진동 변화 를 뮤리듬과 상대파워를 통해 비교분석하여 동작관찰훈련의 신경생 리학적인 변화를 보고하고, 신경가소성 회복을 위한 인지적 측면에 서의 훈련방법으로 제시하고자 한다.

\section{연구방법}

\section{1. 연구대상}

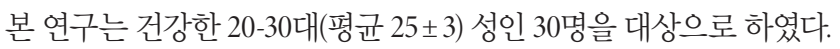
모든 대상자는 신경학적 질환의 병력이 없는 신체적으로 건강한 자, 정상이거나 정상으로 교정된 시력을 지닌 자, 우세손잡이(Edinburgh handedness inventory) 설문에 의해 선별된 오른손잡이인 자로 제한되 었다. ${ }^{20}$ 자발적으로 연구에 참여한 모든 대상자들은 연구의 목적, 잠 재적 이점 및 위험성과 관련된 구체적 설명을 들은 이후, 동의서를 작 성하였다.

\section{2. 실험방법}

\section{1) 실험과정}

모든 대상자들은 조명이 어두운 조용한 방(room)에 들어가 적응시 간을 가지면서 실험에 대한 설명을 들었다. 각 대상자는 편안한 의자 에 앉아 팔꿉관절 약간 굽힘, 아래팔 엎침된 상태로 책상 위에 손을 올려놓았고, ${ }^{18,21}$ 손목 움직임 이외에 불필요한 움직임을 방지하기 위 해 등(back)을 의자에 기대고 앉아 가장 편안한 자세를 취한 후, 실험 이 진행되는 동안에는 움직이지 않을 것을 요구 받았다. 또한 실험자
극이 제시되는 동안에는 전방에 위치한 모니터만 응시하며 눈 깜박 임을 자제할 것을 지시받았다.

모든 대상자는 실험 시작에 앞서 컵을 잡기 위해서는 손목관절의 폄 동작이 선행되어야 한다는 설명을 듣고 연습의 시간을 가졌으며, 이를 바탕으로 실험이 진행되는 동안에는 폄 동작에 집중하여 동작 실행 및 동작관찰을 수행하였다. 휴식 condition 시에는 컴퓨터 모니 터에 나타나는 하얀색 점만을 응시하고 있을 것을 지시 받았고, 실행 condition 시에는 하얀색 점이 파란색 점으로 바뀌면 전방에 놓인 컵 을 잡을 목적으로 손목관절의 폄 동작에 집중하면서 미리 연습한 속 도(동작관찰 영상과 동일한 속도)로 동작을 수행하였다. ${ }^{18}$ 모든 자극 의 시작은 60 초 후에 시작되었고, 동일한 condition에 대해 각 10 회 반 복적으로 시행되었다. 자극 간에는 10 초의 휴식 시간이 제공되었으 며, 각 condition당 220초가 소요되었다. 각 condition 진행은 순서에 의한 효과를 배제하기 위해 무선배치되어 진행되었다.

\section{2) 동작관찰}

동작관찰영상은 $1 \mathrm{~m}$ 앞에 대상자의 눈높이에 높여진 27인치 모니터 에서 제공되었다. 영상 자료는 과제를 수행하는 손(hand)의 움직임을 고해상도 디지털 캠코더로 녹화한 후 실험 목적에 맞도록 편집하였 다. 본 연구에서는 컵을 잡기 위해 움직이는 손의 동작 중 손목관절 폄 동작의 순간에 포커스를 맞추기 위해 동작관찰 영상을 실제적 움 직임의 속도보다 느리게 제공하였다.

동작관찰 condition 시에 모든 대상자는 전방에 위치한 컵을 잡기 위한 손 동작을 관찰하는 동시에 상상할 것을 지시받았다.

\section{3) 뇌파측정}

뇌전도 측정은 24채널 전산화 무선뇌파측정기 Neurofax EEG-1200 (Nihonkhoden corportation, Tokyo, Japan)를 이용하였다. 피질 내에서 의 전기적 활동을 측정하기 위해 금으로 도포된 접시형태의 디스크 전극을 두피에 부착하였으며, 두피와의 접촉 저항을 최소화하기 위 해 알코올 솜을 이용하여 이물질을 닦아내었다. 그런 다음 뇌파 전용 전극 풀(paste)을 묻혀 부착하고 의료용 거즈를 사용하여 고정이 되 도록 처치하였다. 전극은 Jasper (1958)에 의해 발표되고 공인된 '국제 10-20 전극 시스템(international 10-20 electrode system)'에 따라 부착하 였다. 본 연구에서는 $\mathrm{Nz}, \mathrm{A} 1, \mathrm{~A} 2, \mathrm{Fpl}, \mathrm{Fp} 2, \mathrm{Cz}, \mathrm{C} 4, \mathrm{C} 3$ 에 부착하였고 $\mathrm{C} 3$ 의 주변전극 $\mathrm{Cl}, \mathrm{C} 5, \mathrm{FC} 3, \mathrm{PC} 3$ 에도 부착하였다.

뇌에서부터 근육까지의 기능적 연결은 움직이는 신체와 반대측 운동피질에서 발생되게 된다. ${ }^{22}$ 본 연구에서는 오른손의 움직임을 관 찰하는 자극만을 적용하였기 때문에 laplacian algorithm에 의거하여 $\mathrm{C} 3$ 를 활성전극으로 설정하고 주변 전극 $\mathrm{Cl}, \mathrm{C} 5, \mathrm{FC} 3, \mathrm{PC} 3$ 의 평균전위 를 비활성전극으로 설정하는 $\mathrm{AV}$ delete 전극유도를 통해 전위의 차이 


\section{가 계산되었다. $18,21,23$}

뇌파 기록은 잡파(artfacts)의 혼입없이 안정된 뇌파가 지속될 때 측 정을 시작하였고, 모든 자극은 60초 이후에 시작되었다. 측정된 대상 자의 뇌파는 biosignal amplifier (neuropackMEB-2200, Nihon-Koden, Japan)를 통해 12-bit AD 변환된 후 컴퓨터에 저장되었다. 샘플링 주파 수는 Nyquist 이론에 따라 $200 \mathrm{~Hz}$ 로 설정하였다. ${ }^{23}$ 민감도(sensitivity) $10 \mu \mathrm{V}$, 시간상수(time constant) 0.3 초, 고주파 여과 $60 \mathrm{~Hz}$, 저항은 $10 \mathrm{k} \Omega$ 이하로 유지시켰다. $60 \mathrm{~Hz}$ 의 노치 필터링도 함께 해주었다. 눈 깜박임 및 안구의 움직임에 의한 잡파의 혼입은 앞쪽에 위치한 EEG 채널 $(\mathrm{Fpl}, \mathrm{Fp} 2)$ 을 이용해 제거되었고 정확한 window가 아닌 자료는 폐기되 었다. ${ }^{21}$ 잡파 혼입이 많은 대상자의 데이터는 분석에서 제외하여서, ${ }^{18}$ 총 28 명의 뇌파를 분석하였다. 획득된 원(raw)데이터는 매 7초 동안의 자극 중 제시된 시점에 대해 처음 $1 \mathrm{~s}$ 와 마지막 $1 \mathrm{~s}$ 를 제외한 5 초 단위 로 추출되어 분석에 이용되었다.

\section{3. 자료분석}

뮤 억제(mu suppression)는 휴식 시(baseline condition)에 대한 자극 시 (sub condition) 동안의 절대적 파워 비율 차이로 계산되고, 관련 연구 들에서 거울신경 활성의 지표로 많이 활용되고 있는 분석방법 이 다. ${ }^{24-26}$ 절대적 뮤 파워의 비율은 전극 부착 위치, 두피 두께, 전기 저항 과 같은 개인적 차이를 조절하기 위해 사용된다. 그러나 산출된 값들 이 적고 정규적(normal)이지 못하기 때문에 로그변환(log transform) 을 적용한 후 분석에 사용하였다. 계산된 로그 비율이 0 보다 적으면 뮤 억제, 즉 해당 뇌 영역의 활성화가 나타났음을 의미한다. 동작관찰 시와 동작실행 시의 로그비율을 계산하여 일표본 t-test를 실시하였 고, 동작관찰 시와 동작실행 시의 뮤 억제를 비교분석하기 위해 대응 표본 t-test를 실시하였다.

측정된 데이터 속에 각 주파수 성분이 차지하고 있는 비율을 분석 하기 위해 파워스펙트럼(power spectrum) 분석을 실시하였다. 그러나

Table 1. Mu suppression during action execution and action observation $(\mathrm{N}=28)$

\begin{tabular}{lccc}
\hline & Mu suppression & \multicolumn{3}{c}{ Test value $=0$} \\
\cline { 3 - 4 } & & $\mathrm{t}$ & $\mathrm{p}$ \\
\hline Execution & $-0.26 \pm 0.29^{\mathrm{a}}$ & -4.609 & $<0.001^{+}$ \\
Observation & $-0.23 \pm 0.24$ & -5.155 & $<0.001^{+}$ \\
\hline
\end{tabular}

${ }^{a}$ Mean \pm standard deviation.

${ }^{*} p<0.05 ;{ }^{\circ} p<0.01$.

Table 2. Comparison of mu suppression between action execute and action observation $(\mathrm{N}=28)$

\begin{tabular}{ccccc}
\hline & Execution & Observation & $t$ & $p$ \\
\hline mu suppression & $-0.26 \pm 0.29^{a}$ & $-0.23 \pm 0.24$ & 0.295 & 0.77 \\
\hline
\end{tabular}

${ }^{a}$ Mean \pm standard deviation.
두개골 두께의 차이, 측정 당시 긴장도의 차이, 두피상태에 따른 전기 저항의 차이 등에 의해 영향을 받을 수 있음으로 인해 개인의 편차를 줄이고 보정하기 위한 방법으로 상대파워를 비교하였다. 본 연구에 서는 파워스펙트럼을 통해 획득된 진폭값을 제곱(squaring) 처리하 여 절대파워(absolute band power)로 변환한 값을 산출하여 상대파워 분석에 사용하였다. ${ }^{2}$ 계산된 절대 주파수 파워 중에서 눈 깜박임(2$3.9 \mathrm{~Hz})$ 및 머리 움직임 $(0.5-1 \mathrm{~Hz})$ 등에 의해 오염이 될 확률이 높은 델 타파 $(0.5-3.9 \mathrm{~Hz})$ 는 제외하고 $4-50 \mathrm{~Hz}$ 구간만을 추출하여 사용하였다. 상대알파파 $(8-13 \mathrm{~Hz} / 4-50 \mathrm{~Hz})$, 상대낮은베타파 $(14-20 \mathrm{~Hz} / 4-50 \mathrm{~Hz})$, 상 대높은베타파 $(21-30 \mathrm{~Hz} / 4-50 \mathrm{~Hz})$, 상대감마파 $(31-50 \mathrm{~Hz} / 4-50 \mathrm{~Hz})$ 를 분 석하였다. 각 condition에 대한 주파수 대역별 출현량을 비교분석하 기 위해 반복측정 분산분석을 실시하였고 사후검정은 bonferroni를 이용하였다.

모든 분석은 통계 분석 프로그램인 SPSS for Window 20.0을 이용 하여 분석하였고, 통계학적 유의수준 $\mathrm{p}$ 는 0.05 로 정하였다.

\section{결 과}

\section{1. 뮤 억제 비교}

계산된 로그비율을 일표본 t-검정으로 분석한 결과 동작관찰 시와 동작실행 시 모두 뮤 억제가 유의하게 나타났다 $(\mathrm{p}<0.01)$ (Table 1). 두 조건 간의 뮤 억제 차이를 분석하기 위해 대응표본 t-검정을 실시한 결과 유의한 차이가 나타나지 않았다 $(\mathrm{p}>0.05)$ (Table 2).

\section{2. 상대파워 비교}

각 조건에 따른 상대파워의 차이를 알아보기 위해 반복측정된 분산

Table 3. Comparison of relative alpha band power according to each conditions ( $\mathrm{N}=28)$

\begin{tabular}{llcccc}
\hline & Condition & RBP & $F$ & p & Post-hoc \\
\hline Alpha & Rest (a) & $0.31 \pm 0.08^{\mathrm{a}}$ & 11.611 & $<0.001^{+}$ & $\mathrm{a} / \mathrm{bc}$ \\
& Observe (b) & $0.25 \pm 0.07$ & & & \\
& Execute (c) & $0.25 \pm 0.08$ & & & \\
Low Beta & Rest (a) & $0.15 \pm 0.03$ & 3.417 & $<0.040^{*}$ & $\mathrm{a} / \mathrm{c}$ \\
& Observe (b) & $0.15 \pm 0.02$ & & & \\
& Execute (c) & $0.17 \pm 0.04$ & & & \\
High Beta & Rest (a) & $0.30 \pm 0.04$ & 7.486 & $<0.001^{+}$ & $\mathrm{a} / \mathrm{bc}$ \\
& Observe (b) & $0.34 \pm 0.06$ & & & \\
& Execute (c) & $0.34 \pm 0.04$ & & & \\
Gamma & Rest (a) & $0.10 \pm 0.05$ & 3.652 & $<0.033^{*}$ & $\mathrm{a} / \mathrm{b}$ \\
& Observe (b) & $0.13 \pm 0.08$ & & & \\
& Execute (c) & $0.12 \pm 0.08$ & & & \\
\hline
\end{tabular}

${ }^{a}$ Mean \pm standard deviation. RBP: relative band power. ${ }^{*} p<0.05 ;{ }^{*} p<0.01$. 
분석 결과, 각 주파수 파워 대역에서 유의한 차이를 나타내었다 $(\mathrm{p}<0.05)$ (Table3).

Bonferroni방법을 이용한 사후검정결과 상대알파파워는 동작관 찰 시와 동작실행 시에 휴식 시에 비해 감소되는 유의한 차이를 나타 내었다 $(\mathrm{p}<0.05)$. 상대높은베타파워는 휴식 시에 비해 동작실행 시에 증가되는 유의한 차이를 보여주었지만 $(\mathrm{p}<0.05)$, 휴식 시와 동작관찰 시 간에는 유의한 차이를 나타내지 않았다( $\mathrm{p}>0.05)$. 높은베타파워는 휴식 시에 비해 동작관찰 시와 동작실행 시에 증가되는 유의한 차이 가 나타났고 $(\mathrm{p}<0.05)$, 감마파워는 휴식 시와 동작관찰 시 간에만 증 가되는 유의한 차이를 보여주었다 $(\mathrm{p}<0.05)$. 모든 주파수 대역에서 동 작관찰 시와 동작실행 시 사이의 유의한 차이는 나타나지 않았다 $(\mathrm{p}>0.05)$.

\section{고 찰}

최근 거울신경시스템의 활성에 근거하여 동작관찰 동안 실제 움직임 에 관여하고 있는 뇌영역이 유사한 활성을 만들어 낸다고 보고되고 있고, ${ }^{27}$ 이에 운동 학습 능력을 극대화시키기 위한 인지적 재활의 방 법으로 활발히 연구가 진행 중에 있다.

본 연구에서는 동작관찰 시에 나타나는 뇌전도상의 신경생리학적 인 변화를 뮤 억제와상대파워 분석을 통해 동작실행 시와 비교하고 자 하였다. 움직임의 관찰 및 실행과 관련이 있는 감각운동피질의 활 성은 움직이는 해당 신체의 반대쪽에서 나타나므로 C3 영역에서의 변화만을 분석에 사용하였다.

그 결과 휴식 시에 비해 동작실행 시에 뮤 억제가 유의하게 나타났 고 $(\mathrm{p}<0.01)$, 동작관찰 시에도 휴식 시에 비해 뮤 억제가 유의하게 나 타나는 것을 확인하였다 $(\mathrm{p}<0.01)$. 그러나 두 조건 간의 뮤 억제 차이 는 유의하게 나타나지 않았다 $(\mathrm{p}>0.05)$. 이는 동작실행 및 동작관찰 모두 동일한 뇌 영역의 거울신경시스템 활성을 유발한다는 것을 보 여주고, 또한 동작관찰만으로도 실제 움직임 시와 유사하게 감각운 동피질의 활성을 유도할 수 있음을 간접적으로 보여주는 결과라고 생각된다. 이는 Muthukumaraswamy와 Johnson ${ }^{28}$, Perry와 Bentin ${ }^{29}$, Shahid 등 ${ }^{30}$ 의 연구결과와도 일치한다. 또한 Puzzo 등 ${ }^{31}$ 과 Pineda ${ }^{12}$ 는 뮤리듬의 변화는 감각운동피질의 억제성 활성 지표로서, 거울신경시 스템 활성의 EEG maker로 생각할 수 있다고 주장하기도 하였다. 이러 한 신경생리학적인 변화는 $\mathrm{Kim}$ 과 $\mathrm{Kim}^{32}$ 의 연구에서와 같이 뇌졸중 환자의 보행능력을 향상시키는 결과로 이어졌을 것으로 추측되고, 이는 재활의 중재과정에서 동작관찰 훈련이 손상된 뇌의 재구성과 함께 기능적 증진을 촉진할 수 있는 긍정적 효과를 보여주는 것이라 여겨진다.

각각의 뇌파는 뇌 기능의 다른 상태를 반영한다. 알파파 $(8-13 \mathrm{~Hz})$
는 기본적 뇌파파형으로서 정상성인의 안정적 휴식상태, 편안한 자 각 상태에서 나타나게 되므로 뇌의 이완상태를 반영한다고 간주되 고 있다. 알파밴드 대역 주파수 파워는 동작의 실행 혹은 관찰에 의 해서 감소되고, 감각운동과제와 매우 밀접한 관련을 가진다고 알려 져 있다. ${ }^{13-15}$ 본 연구에서도 알파대역의 상대파워는 동작 실행 및 관 찰 모두에 의해 유의한 감소 $(\mathrm{p}<0.01)$ 를 나타내는 것으로 나타났다. 베타파 $(13-30 \mathrm{~Hz})$ 는 파형이 불규칙하고 진폭이 낮은 짧은 속파로서, 인지과정이나 집중이 요구되는 비교적 정신 부하가 높은 사고활동 을 수행할 때 우세하게 나타나게 되고,3334 감각 정보의 입력증가, 감 각통합 및 운동실행과 매우 밀접한 관련성을 가지고 있다.21

손가락 또는 손목관절 움직임 동안 감각운동피질에서 베타파(12$20 \mathrm{~Hz}$ )의 진폭이 감소되는 비동기화가 나타나고, ${ }^{12,15,35}$ 움직임이 끝난 이후에 진폭이 증가하게 되는 동기화가 나타난다고 보고되고 있지 만 ${ }^{23}$ Houdayer 등 ${ }^{21}$ 의 연구에서는 손가락 움직임에 의해 베타대역(13$25 \mathrm{~Hz}$ )의 동기화가 나타났다고 보고하였고, 이는 근육, 관절, 피부로 부터의 감각 입력을 처리하는 피질 활동을 반영하는 결과라고 주장 하였다. 본 연구에서는 낮은베타 $(14-20 \mathrm{~Hz})$ 와 높은베타 $(21-30 \mathrm{~Hz})$ 모 두에서 동작실행에 의해 상대파워가 유의하게 증가하는 것으로 나 타났지만 $(\mathrm{p}<0.01)$, 낮은베타파워는 동작실행에 의해서만 유의한 증 가를 나타내었다 $(\mathrm{p}<0.01)$. 낮은베타파워 대역에서 동작관찰 시에 유 의한 차이가 나타나지 않은 것은 언급된 선행연구들과는 달리 베타 주파수대역을 세분화하여 절대파워가 아닌 상대파워로 분석하였고, 또한 동작실행 시에 비해 동작관찰 시에 과제에 대한 집중과 몸 감각 의 자극이 상대적으로 부족하였기 때문일 것으로 추측할 수 있다. 높 은베타파워는 긴장, 흥분 및 스트레스 상태를 반영하고, 낮은 베타파 워는 집중과 정신적 활동상태를 반영한다고 알려져있다. 알파(8-13 $\mathrm{Hz})$ 와 베타 $(14-30 \mathrm{~Hz})$ 주파수 밴드에서의 진동활동은 감각운동과제 와 밀접하게 연관되어 나타나게 되므로, ${ }^{13,36}$ 이에 대한 관찰은 입력된 감각정보의 처리과정에 대한 유용한 방법이 될 수 있을 것으로 생각 된다.

감마밴드는 집중과 기억과 같은 인지적 기능(cognitive functions)과 관련이 깊으므로 신경활동 생산의 지표로 여겨지고, 움직임 생산과 가장 밀접한 관련을 가지고 있으므로 행동과 관련된 기능적 변화의 지표가 될 수 있다.22 감마파의 동기화는 움직임의 실행 동안과 공간 에서의 시각적 집중이 이뤄지는 동안에 나타난다고 보고되고 있으 나 $^{8}$, 본 연구에서는 동작관찰 시에만 유의한 증가를 나타내었다 $(\mathrm{p}<0.01)$. 일상생활 속에서 컵과 같은 사물을 잡는 동작을 무수히 반 복하고 있지만, 손목관절의 폄이라는 동작은 의식하지 않은 채 손가 락을 이용하여 잡는다고 인식하고 있다. 그렇기 때문에 손목관절의 폄이라는 동작을 관찰과 동시에 상상하기 위해서는 더 많은 인지적 과정이 동원되어야 했기 때문일 것으로 추측되고, 반면 실제적 동작 
수행 시에는 천천히 수행할 것을 지시받았기는 하지만 이미 충분히 학습되어 있는 아주 쉬운 동작이었기 때문에 상대감마파워에 미치 는 영향이 적었을 것으로 추측된다.

주목할 만한 점은 모든 주파수 영역에 걸쳐서 동작실행과 동작관 찰 시에 상대파워의 차이가 나타나지 않았다는 것이다. 이는 동작실 행과 동작관찰이 동일한 뇌영역의 유사한 뇌활성을 유발시킨다는 것 을 간접적으로 보여주는 증거라고 판단되고, 신체적 움직임이 제한되 어 있는 대상자들에게 인지적 재활의 방법으로 적용하기에 적절한 대안적 중재 수단이 될 수 있음 것임을 증명하는 것이라 사료된다.

본 연구는 동작실행과 동작관찰 시의 뇌활성 변화를 관찰하기 위 해 뇌전도를 활용하여 실시되었고, 뮤 리듬과 상대파워를 통해 비교 분석한 결과 두 조건 모두에서 감각운동피질의 활성을 유발해 내는 것으로 확인되었다. 이는 동작관찰훈련의 신경생리학적인 긍정적 변 화를 증명하는 결과로써 뇌가소성 증대를 통해 기능적 변화를 이끌 어 낼 수 있는 근거를 간접적으로 제시하는 것이라 생각된다.

\section{참고문헌}

1. Reynolds C, Osuagwu BA, Vuckovic A. Influence of motor imagination on cortical activation during functional electrical stimulation. Clin Neurophysiol. 2015;126(7):1360-9.

2. Kang HG. A study of brain activity during grasping and supination using EEG analysis. Seoul, University of Science \& Technogogy, 2013.

3. Mouthon A, Ruffieux J, Walchli M et al. Task-dependent changes of corticospinal excitability during observation and motor imagery of balance tasks. Neuroscience. 2015;303:535-43.

4. Johansson BB. Current trends in stroke rehabilitation. A review with focus on brain plasticity. Acta Neurologica Scandinavica. 2011;123(3):14759.

5. Small SL, Buccino G, Solodkin A. The mirror neuron system and treatment of stroke. Developmental Psychobiology. 2012;54(3):293-310.

6. Rizzolatti G, Craighero L. The mirror-neuron system. Annual Review of Neuroscience. 2004;27:169-4.

7. Kim SH, Cho JS. Action observation and cortical connectivity: Evidence from EEG analysis. J Kor Phys Ther. 2016:28(6):398-407.

8. Schoffelen JM, Poort J, Oostenveld R et al. Selective movement preparation is subserved by selective increases in corticomuscular gamma-band coherence. J Neurosci. 2011;31(18):6750-8.

9. Chatrian GE, Petersen MC, Lazarte JA. The blocking of the rolandic wicket rhythm and some central changes related to movement. Electroencephalography And Clinical Neurophysiology. 1959;11(3):497-510.

10. Gastaut HJ, Bert J. EEG changes during cinematographic presentation (moving picture activation of the EEG). Electroencephalography And Clinical Neurophysiology. 1954;6(0):433-44.

11. Sabate M, Llanos C, Enriquez E et al. Mu rhythm, visual processing and motor control. Clinical Neurophysiology. 2012;123(3):550-7.

12. Pineda JA. The functional significance of mu rhythms: translating "seeing" and "hearing" into "doing”. Brain Research Reviews. 2005;50:57-68.
13. Hari R. Brain rhythms and reactivity of the human motor cortex. International Congress Series. 2002;1226(0):87-95.

14. Hari R. Action-perception connection and the cortical mu rhythm. Progress in Brain Research. 2006;159:253-60.

15. Babiloni C, Babiloni F, Carducci F et al. Human cortical electroencephalography (EEG) rhythms during the observation of simple aimless movements: a high-resolution EEG study. NeuroImage. 2002;17(2):55972 .

16. Muthukumaraswamy SD, Johnson BW, McNair NA. Mu rhythm modulation during observation of an object-directed grasp. Cognitive Brain Research. 2004;19(2):195.

17. Kim SH. A neuroscientific approach to the relationship between creativity and knowledge. Korea National University. Dissertation of Master's Degree. 2010.

18. Muller-Putz GR, Zimmermann D, Graimann B et al. Event-related beta EEG-changes during passive and attempted foot movements in paraplegic patients. Brain Res. 2007;1137:84-91.

19. Noh HJ. Effects of gradually decreasing action observation training on stroke patients balance and gait ability . Daejeon University. Dissertation of Doctorate Degree. 2015.

20. Divekar NV, John LR. Neurophysiological, behavioural and perceptual differences between wrist flexion and extension related to sensorimotor monitoring as shown by corticomuscular coherence. Clin Neurophysiol. 2013;124:136-47.

21. Houdayer E, Labyt E, Cassim F et al. Relationship between event-related beta synchronization and afferent inputs: analysis of finger movement and peripheral nerve stimulations. Clin Neurophysiol. 2006;117(3):62836.

22. Fang Y, Daly JJ, Sun J et al. Functional corticomuscular connection during reaching is weakened following stroke. Clin Neurophysiol. 2009; 120(5):994-1002.

23. Müller GR, Neuper C, Rupp R et al. Event-related beta EEG changes during wrist movements induced by functional electrical stimulation of forearm muscles in man. Neurosci Lett. 2003;340(2):143-7.

24. Oberman LM, Ramachandran VS, Pineda JA. Modulation of mu suppression in children with autism spectrum disorders in response to familiar or unfamiliar stimuli: the mirror neuron hypothesis. Neuropsychologia. 2008;46(5):1558-65.

25. Bernier R, Dawson G, Webb S et al. EEG mu rhythm and imitation impairments in individuals with autism spectrum disorder. Brain \& Cognition. 2007;64(3):228-37.

26. Pineda JA, Hecht E. Mirroring and mu rhythm involvement in social cognition: are there dissociable subcomponents of theory of mind? Biological Psychology. 2009;80(3):306-14.

27. Grèzes J, Decety J. Functional anatomy of execution, mental simulation, observation, and verb generation of actions: a meta-analysis. Human Brain Mapping. 2001;12:1-19.

28. Muthukumaraswamy SD, Johnson BW. Changes in rolandic mu rhythm during observation of a precision grip. Psychophysiology. 2004;41:1526.

29. Perry A, Bentin S. Mirror activity in the human brain while observing hand movements: a comparison between EEG desynchronization in the mu-range and previous fMRI results. Brain Research. 2009;1282:12632 . 
30. Shahid S, Sinha RK, Prasad G. Mu and beta rhythm modulations in motor imagery related post-stroke EEG: a study under BCI framework for post-stroke rehabilitation. BMC Neuroscience. 2010;11:1-2.

31. Puzzo I, Cooper NR, Vetter P et al. EEG activation differences in the premotor cortex and supplementary motor area between normal individuals with high and low traits of autism. Brain Research. 2010;1342:104-10.

32. Kim JS KK. Clinical feasibility of action observation based on mirror neuron system on walking performance in post stroke patients. J Phys Ther Sci. 2012;24:597-9.

33. Ahn BM. EEG analysis for design of brain-computer interface(BCI)
Korea National University of Education. Dissertation of Master's Degree. 2010 .

34. Lee SL. EEG analysis of concentrativeness due to visual stimulus task. Pukyong National University. Dissertation of Master's Degree. 2014.

35. Oberman LM, Hubbard EM, McCleery JP et al. EEG evidence for mirror neuron dysfunction in autism spectrum disorders. Cognitive Brain Research. 2005;24(2):190-8.

36. Pfurtscheller G, Brunner C, Schlögl A et al. Mu rhythm (de)synchronization and EEG single-trial classification of different motor imagery tasks. NeuroImage. 2006;31:153-9. 